\section{OS JOGOS PAN-AMERICANOS E 0 ENRAIZAMENTO DO MOVIMENTO OLÍMPICO NA AMÉRICA LATINA}

\author{
THE PAN-AMERICAN GAMES AND THE ESTABLISHMENT OF THE OLYMPIC \\ MOVEMENT IN LATIN AMERICA
}

Doiara Silva dos Santos*
Palavras chave:

História.

América Latina.

Movimento

Olímpico.

\begin{abstract}
Resumo: 0 objetivo desta pesquisa é discutir o processo histórico de estabelecimento dos Jogos Pan-Americanos (Pan) e o processo de enraizamento do Movimento Olímpico na América Latina. A coleta de dados reúne fontes primárias das décadas de 1940 e 1950, a saber: documentos oficiais do Comitê Olímpico Internacional (COI), da Organização Pan-Americana de Desportos (ODEPA), dentre outros. A análise dos dados foi realizada a partir da produção de uma narrativa histórica. Dois argumentos se destacaram em relação à proposta de estabelecer os Jogos Pan-Americanos: 1. 0 papel diplomático dos Jogos; 2. A visão idealística implicada no evento.
\end{abstract}

Keywords:

History.

Latin America.

Olympic Movement.
Abstract: This research discusses the historical process of establishment of the PanAmerican (Pan-Am) Games and the Olympic Movement in Latin America. The data collection stage gathered primary sources from 1940 and 1950, namely: official documents of the International Olympic Committee (IOC), the Pan-American Sports Organization (PASO), and others. Data analysis was performed by producing a historical narrative. Two arguments stood out in the proposal to establish the Pan-American Games: 1. The diplomatic role they played; 2 . The idealistic view involved in the event.

Palabras clave: Historia. América Latina. Movimiento Olímpico.
Resumen: El objetivo de esta investigación es analizar el proceso histórico de creación de los Juegos Panamericanos y el proceso de arraigo del movimiento olímpico en Latinoamérica. La recolección de datos reúne fuentes primarias de las décadas de 1940 y 1950, a saber: documentos oficiales del Comité Olímpico Internacional (COI), de la Organización Deportiva Panamericana (ODEPA) y otros. El análisis de datos se realizó a partir de la producción de una narrativa histórica. Dos argumentos se destacaron en la propuesta de establecer los Juegos Panamericanos: 1. El papel diplomático de los Juegos; 2. La visión idealista que es parte del evento.
*Professora Adjunta da Universidade Federal de Viçosa. Viçosa, MG, Brasil. E-mail: doiarasantos@yahoo.com.br

Recebido em: 24-04-2017 Aprovado em: 31-05-2017

(c) (i) () Licence 


\section{INTRODUÇÃO}

Os Jogos Olímpicos e Paralímpicos do Rio de Janeiro em 2016 captaram a atenção e interesse, nos cenários nacional e internacional, de pesquisadores que investigam o esporte moderno (em geral) e os Jogos Olímpicos (em específico) quanto a aspectos políticos, econômicos, ideológicos e sociais indissociavelmente ligados a esses fenômenos, em um contexto raro nos mais de cem anos de história do Movimento Olímpico moderno: a América Latina.

Esses eventos recentes somaram diversas problematizações à relação histórica entre a América Latina e o Movimento Olímpico, as quais possibilitam uma variedade de vias de análise e interpretações em perspectivas socioantropológicas. Entretanto, ao longo da história, eventos como os Jogos Pan-Americanos influenciaram e moldaram a relação entre a América Latina e o Movimento Olímpico.

Inaugurados em 1951 com a chancela do COI, os Jogos Pan-Americanos (Pan) apresentam-se como um evento consolidado, que ocorre de quatro em quatro anos, com crescente organização e alcance. Com base no levantamento bibliográfico realizado para este estudo, enquanto os Jogos Olímpicos modernos são escrutinados como foco de atenção e análise quanto aos seus impactos financeiros, midiáticos, turísticos, políticos, com temas como corrupção, gênero e doping, o Pan tem sido menos investigado na literatura acadêmica nacional e internacional, negligenciando-se, em grande medida, as influências e implicações sócio-históricas do evento para a região (SANTOS, 2015).

Tal como os Jogos Olímpicos, o Pan pode ser entendido como um megaevento, uma vez que se apresenta como um evento cultural esportivo de larga escala, que tem caráter dramático, apelo popular de massa e significado internacional (ROCHE, 2000). Considerandose a adjetivação destacada por Tavares (2011), os jogos Pan-Americanos são, em específico, megaeventos esportivos e, como tal, apresentam-se como um campo de investigação fértil para problematizações que podem perpassar questões econômicas, políticas, culturais e sociais.

Este estudo estabelece como pressuposto que investigar as bases históricas do evento continental mais duradouro chancelado pelo Comitê Olímpico Internacional (COI) pode contribuir para o entendimento sobre a articulação entre as culturas esportivas da América Latina e o Movimento Olímpico em relação s seu arcabouço ideológico e cultural.

Assim, o objetivo principal desta pesquisa é discutir o processo histórico de estabelecimento dos Jogos Pan-Americanos e suas implicações para a relação entre a América Latina e o Movimento Olímpico moderno. Tem-se como objetivos específicos: examinar as bases históricas para a inauguração dos Jogos Pan-Americanos; investigar o desenvolvimento dos Jogos Pan-Americanos nas Américas em seus primeiros anos de existência; discutir as implicações sócio-históricas deste evento para a relação entre a América Latina e o Movimento Olímpico.

Os dados coletados são documentos oficiais do COI, da Organización Deportiva Panamericana (ODEPA), correspondências e outros arquivos que estão disponíveis na Coleção Avery Brundage. Essa coleção de arquivos históricos está disponível em poucas universidades e bibliotecas do mundo. Foi catalogada, organizada, preservada e disponibilizada para acadêmicos de várias nacionalidades, que têm publicado suas pesquisas na área de 
estudos olímpicos, principalmente, em periódicos internacionais. 0 nome dado à coleção é 0 do primeiro presidente da ODEPA e presidente do COI por mais de 20 anos, que selecionou, arquivou e armazenou tais documentos. Por essas razões, os documentos dessa coleção apresentam relação direta com o objeto de análise desta pesquisa. Trata-se de fontes primárias, armazenadas em microfilme (mídia analógica). A consulta a esses materiais foi realizada no Centro Internacional de Estudos Olímpicos, na Western University, Canadá, como parte do desenvolvimento de uma pesquisa de doutorado. Para esta análise, foram incluídos documentos que datam da década de 1940 e década de 1950, período entre a idealização e materialização dos Jogos Pan-Americanos.

Esta pesquisa é qualitativa e tem caráter descritivo. De tal modo, envolve o estudo e avaliação aprofundados de informações na tentativa de explicar o contexto de um fenômeno, neste caso, o estabelecimento dos Jogos Pan-Americanos. Para o tratamento dos dados, utilizou-se como técnica a análise documental para a produção de uma narrativa histórica. Em uma pesquisa histórica, a análise de fontes documentais exige uma articulação do pesquisador com os acontecimentos históricos que as circundam. Estudos baseados em documentos como material primordial extraem deles toda a análise, organizando-os e interpretando-os segundo os objetivos da investigação proposta (PIMENTEL, 2001). Todos os documentos encontrados na coleção Avery Brundage estão redigidos em inglês ou em espanhol e, para esta análise, a tradução para o português é de responsabilidade da autoria.

\section{AS BASES HISTÓRICAS DOS JOGOS PAN-AMERICANOS}

Para tornar o Movimento Olímpico global/universal o COI endossou, embora não sem resistências, competições regionais e continentais no início do século XX. Houve intensos debates em reuniões consecutivas do órgão para decidir sobre chancelar e sediar Jogos regionais. De um lado havia a preocupação de que a proliferação de jogos regionais pudesse, a longo prazo, fazer declinar o interesse pelos Jogos Olímpicos. Do ponto de vista favorável estava a finalidade/mensagem ideológica de promover o esporte moderno, o Movimento Olímpico e construir um evento que, de fato, refletisse a proposta de internacionalização do barão francês Pierre de Coubertin. ${ }^{1}$

Na história, em uma era que antecede a noção de megaeventos esportivos, identificamse dois precedentes de eventos regionais nas Américas. Torres (2012) investigou a primeira competição multiesportiva regional realizada com o endosso do COI, que ocorreu no Rio de Janeiro, em 1922. Em conjunto com celebrações para o centenário da independência no Brasil, a competição foi denominada, a princípio, de Jogos Olímpicos Latino-Americanos e, posteriormente, Jogos Latino-Americanos. $O$ evento aconteceu com a colaboração operacional da Associação Cristã de Moços (ACM), envolto por ideais de "cristandade muscular". A ACM promoveu o esporte como essencial para a formação moral e cristã e tornou-se reconhecida por ter contribuído para o desenvolvimento do esporte moderno no mundo no século XX e, também, para a expansão do Movimento Olímpico.

Em 1926, também com o endosso do COI em parceria com a ACM, foram realizados os Jogos Centro-Americanos, no México, vistos como um marco para o desenvolvimento do esporte e dos ideais olímpicos naquele país (MCGEHEE, 1993). Essa competição acontece

1 COMITÊ OLÍMPICO INTERNACIONAL. Minutas da Sessão de Viena. Comitê Executivo do COI, Viena, v. 31, p. 52, 3 maio 1951. 
até os dias atuais. Entretanto, as análises históricas sobre os Jogos de 1922 no Rio e os Jogos Centro-Americanos são isoladas. Neste estudo, constrói-se o argumento de que esses dois eventos podem ser compreendidos como precursores e propulsores da ideia de se realizar o evento continental mais tarde denominado de Jogos Pan-Americanos, a julgar pela mobilização que eles desencadearam para a criação de federações esportivas nacionais e regionais, filiação de membros da América Latina ao COI, criação de Comitês Olímpicos Nacionais (CON) em países das Américas Central e do Sul, e pela apropriação/emulação das dimensões protocolares, operacionais e ideológicas dos Jogos Olímpicos nesses eventos.

A proposição de realizar jogos entre países do continente americano amadureceu anos mais tarde e apareceu com mais elaboração e de maneira mais explícita na década de 1940, como se analisará na seção a seguir.

\subsection{Avery Brundage: panamericanismo e idealismo olímpico}

Uma figura muito importante para a consolidação do Movimento Olímpico e para a história dos Jogos Pan-Americanos foi o ex-atleta olímpico e administrador esportivo norte-americano Avery Brundage. Personagem importante e controverso quanto a seus posicionamentos ideológicos e políticos, a vida e o trabalho de Brundage são bastante conhecidos na literatura acadêmica internacional sobre estudos olímpicos, mas pouco mencionados na produção brasileira da área.

Dentre outras questões, Brundage se opunha à comercialização dos Jogos, negava a influência da política ou do contexto político sobre o esporte (e vice-versa), defendia 0 amadorismo esportivo ${ }^{2}$ e, com muita veemência, defendia a continuidade dos Jogos Olímpicos a despeito de condições adversas. Nas décadas de 1930 e 1940, ele se tornou uma autoridade proeminente em instituições esportivas americanas e no COI, após mediar as ameaças de boicote aos Jogos Olímpicos de 1936 na Alemanha sob o domínio nazista. Devido a essa posição de destaque, ele foi o canal de comunicação para a formalização e operacionalização das propostas de se realizarem Jogos Pan-Americanos.

É importante ressaltar que as práticas de Brundage como dirigente esportivo, numa análise geral, foram consideradas por muitos de seus contemporâneos e estudiosos como autoritárias e arbitrárias (GUTTMANN, 1984; SENN, 1998). O fato é que entre as décadas de 1930 e 1970, Brundage protagonizou acontecimentos importantes para a história dos Jogos Olímpicos e Pan-Americanos, inclusive tornando-se o presidente das duas instituições responsáveis por cada um desses eventos.

Conforme se constatou nos estudos de Torres (2011), a princípio, o Pan foi proposto como uma forma de cooperar para o espírito do "pan-americanismo", a fim de fortalecer os laços econômicos, políticos, e a interlocução cultural pelo continente, portanto, com finalidade diplomática, em consonância com a política externa do então presidente americano Franklin Roosevelt. Os dados obtidos a partir desta pesquisa somam às análises de Torres (2011) o fato de que Brundage via nos Jogos Pan-Americanos não apenas uma oportunidade diplomática,

2 Amadorismo esportivo compreendido por ele como o atleta que não recebe qualquer benefício financeiro ou patrocínio para a prática de esportes, estes considerados profissionais.

3 O "pan-americanismo" foi o nome dado a uma das políticas do presidente dos EUA, Franklin Roosevelt, que tinha dentre os seus principais princípios a não intervenção e não interferência externa nas questões da América Latina e a criação de oportunidades econômicas e acordos 
mas uma forma de promover os ideais olímpicos (do modo como ele próprio interpretava e acreditava).

Diante do interesse do Comitê Olímpico Argentino (COA) em organizar e sediar a primeira edição do Pan, Brundage, diligentemente, viajou para Buenos Aires e outros países da América do Sul (como Peru, Brasil e Colômbia), participando de reuniões e planejamentos para a organização da competição no futuro. A iminência da II Guerra Mundial e o cancelamento oficial dos Jogos Olímpicos de 1940 trouxeram a Brundage a ideia de que cabia ao ocidente "manter as mais puras tradições do esporte amador" (GUTTMANN, 1984, p. 88).

Brundage tornou-se o presidente eleito da ODEPA no I Congresso Pan-Americano de Desportos, realizado para formalizar os planos de organização do evento em Buenos Aires, em 1940. Ele era o único membro não latino na ocasião da formação da organização e, ainda assim, tamanha a sua influência internacional, foi eleito pela maioria dos presentes como presidente daquela instituição. Durante a sua viagem, conforme demonstram os documentos analisados, Brundage conciliou elementos ideológicos e diplomáticos para ratificar a importância da proposta do evento continental, conforme se constata em trecho de um de seus discursos no Peru, em que ele defendia:

[...] a formação de uma organização esportiva que contribua mais que qualquer outra atividade humana para o cultivo de amizade e entendimento mútuo entre nações do continente americano, especialmente quando tantas forças que objetivam a destruição de ideais humanos estão engajadas numa luta devastadora [...] Eu acredito que 0 atual momento de turbulência mundial é precisamente quando as três Américas devem buscar demonstrar o máximo do que são, por si mesmas, capazes de iniciar e realizar os Jogos Olímpicos Pan-Americanos [...] para mostrar em grande estilo que o esporte é a única atividade livre de invejas maliciosas, rivalidades e armadilhas. ${ }^{4}$

Brundage foi o responsável por associar objetivos ideológicos à realização do Pan, ao mencionar, utilizando o termo Jogos "Olímpicos" Pan-Americanos. Ao mencionar uma "luta devastadora", Brundage referia-se à eclosão da II Guerra Mundial. Ele retornou aos EUA otimista em seus relatos à Associação Olímpica Americana (AOA). Tal entusiasmo foi consubstanciado por ações imediatas de burocratização da ODEPA, propondo normas para redigir o livro de regras e regulamentos, estabelecendo os cargos e funções da organização e estimulando a filiação de membros das três Américas, criando um forte networking.

Brundage enfatizou, com o cuidado de resguardar suas devidas proporções, o aumento do turismo e os benefícios financeiros que sediar um evento multiesportivo poderia trazer a uma cidade, citando como exemplos os Jogos Olímpicos de Los Angeles de 1932 e de Berlim, em 1936.

Nos documentos analisados foi possível identificar uma dificuldade em relação à jurisdição dos Jogos continentais das Américas. Brundage insistia para que o Pan seguisse os moldes dos Jogos Olímpicos e que os membros do COI chancelassem o evento. Membros do COA, por sua vez, escreveram para Brundage em 1940 afirmando que "não se poderia pensar que a organização dos Jogos Pan-Americanos seria realizada por cavalheiros de países europeus"s. Brundage respondeu:

Nós aqui nos Estados Unidos compartilhamos a mesma visão que os senhores da América do Sul quanto a este assunto. Estes Jogos são parte de uma instituição

\footnotetext{
4 BRUNDAGE, Avery. Discurso proferido em Recepção ao Comitê Esportivo Peruano, 1940a. Coleção Avery Brundage, Western University, Caixa 202, Bobina de Microfilme n.116.

5 COMITÊ OLÍMPICO ARGENTINO. [Carta] 4 nov. 1940, Buenos Aires [para] BRUNDAGE, Avery. Chicago. 1 f. Organização dos Jogos
} Pan-Americanos. Coleção Avery Brundage, Caixa 202, Bobina de Microfilme n.116. 
americana que deve ser controlada de maneira democrática e exclusivamente por americanos. Eu sugeri a adoção de regulações das federações internacionais porque são satisfatórias em uso comum, e não porque devemos soberania a qualquer outra organização [...] lamento que tenha havido um desentendimento causado por interpretações inapropriadas [...] a visão dos verdadeiros cavalheiros do esporte amador aqui dos Estados Unidos são as mesmas daqueles na Argentina [grifo meu]. ${ }^{6}$

Note-se que o termo "americano" tem uma referência identitária continental neste caso. E, embora Brundage tenha concordado com uma relativa autonomia da recém-criada instituição, ele insistiu e defendeu que a ODEPA seguisse normas e protocolos que balizavam os próprios Jogos Olímpicos. Essa negociação que perpassa jurisdição, modelo protocolar e organizacional atravessou outras questões. A proteção da palavra "olímpico" foi tema de correspondência de Brundage endereçada a membros do COA, como se verifica a seguir:

Recebi uma carta do presidente do Comitê Olímpico Internacional que está muito preocupado porque os Jogos a serem celebrados em Buenos Aires têm sido incorretamente chamados de "Jogos Olímpicos Pan-Americanos" em jornais e outras publicações. Eu irei informá-lo que isso não partiu da ODEPA. Existe, é claro, apenas um "Jogos Olímpicos" e o uso inapropriado do termo pode resultar em grande confusão. Confio que vocês farão de tudo em seu poder para impedir erros deste tipo. Deem proeminência às publicações oficiais da ODEPA para corrigir o problema.7 (BRUNDAGE, 1941, sem página, grifo do autor).

Apesar da crescente burocratização da instituição e constante comunicação entre os membros da recém-criada ODEPA, a tentativa inicial de inaugurar os Jogos Pan-Americanos em 1940 em Buenos Aires, na Argentina, sucumbiu ao cenário da II Guerra Mundial. Além das questões de segurança, transporte de atletas e outras dificuldades, com a participação protagonista dos EUA na Guerra, a relação entre este país e a Argentina quanto a seus posicionamentos políticos ficou tensionada naquele cenário e comprometeu decisivamente operacionalidade do evento regional ${ }^{8}$. Esses mesmos motivos fizeram com que a tentativa de inaugurar o evento em 1942 também falhasse (TORRES, 2011).

Apesar do adiamento do evento em duas ocasiões, a articulação entre as autoridades do esporte foi mantida pelos membros do COA por meio de correspondências frequentes com Brundage, racionalizando a possibilidade de retomada dos planos de inaugurar o evento. Com o fim da II Guerra em 1946, os articuladores do Pan nas Américas agendaram novas reuniões e congressos na oportunidade dos Jogos Olímpicos de Londres em 1948.

\section{O PERONISMO NA ARGENTINA E OS JOGOS PAN-AMERICANOS DE 1951}

Embora a literatura internacional sobre o esporte tenha dedicado pouca atenção ao cenário pós II Guerra Mundial na América Latina, é importante destacar que, entre as décadas

\footnotetext{
6 BRUNDAGE, Avery. [Carta] 5 Dez. 1940b, Chicago [para] PALACIOS, Juan Carlos. Buenos Aires. 1f. Organização dos Jogos PanAmericanos. Coleção Avery Brundage, Western University, Caixa 202, Bobina de Microfilme n.116.

7 BRUNDAGE, Avery. [Carta] 24 Nov. 1941, Chicago [para] PALACIOS, Juan Carlos. Buenos Aires. 1f. Organização dos Jogos PanAmericanos. Coleção Avery Brundage, Western University, Caixa 202, Bobina de Microfilme n.116.

8 No início do século XX, a influência alemã na Argentina era forte, principalmente devido ao grande número de imigrantes alemães na Argentina. Tal influência cresceu continuamente antes das duas guerras mundiais. $O$ exército argentino cultivava admiração pelo exército alemão. Leonard e Bratzel (2006) encontraram evidências de que muitos militares argentinos foram simpatizantes de Adolf Hitler. Apesar das disputas internas e pressões dos EUA para juntar-se aos Aliados durante a II Guerra Mundial, o laço estreito entre Alemanha e Argentina foi uma das razões que fizeram com que a Argentina se mantivesse neutra durante grande parte da ll Guerra. A Argentina cedeu à pressão dos EUA e declarou Guerra às potências do eixo tardiamente naquela Guerra.
} 
de 1950 e 1960, países da América Central e do Sul foram controlados por regimes militares e ditatoriais. Foi neste contexto que o Pan se materializou e desenvolveu. A história do Pan, com isso, centraliza-se, a princípio, entre personagens argentinos e norte-americanos.

Ao longo da década de 1940, a Argentina, país da futura sede da inauguração do Pan, passou por profundas mudanças que afetaram as políticas esportivas do país. Em 4 de junho de 1943, um golpe de Estado destituiu o governo de Ramón Castillo, que presidiu mais de uma década de governo oligárquico na Argentina. $O$ coronel Juan Domingo Perón venceu eleições diretas em 1946, com o apoio de sindicalistas e da classe trabalhadora. O presidente Perón estabeleceu o esporte como um fenômeno de suma importância para o Estado dentro de um regime nacionalista e populista (TORRES, 2014).

Brundage, previsivelmente, se deparou com grandes entraves na tentativa de impedir que governos das três Américas interferissem na composição ou formação de entidades esportivas, sobretudo seus respectivos CON . Em reunião do Comitê Executivo do COI em Lausanne, em 1949, Brundage expressou preocupação com as "intrusões de governos militares das Américas do Sul e Central sobre as organizações esportivas". ${ }^{10}$

De fato, o governo peronista destituiu membros do COA e novos integrantes assumiram o papel de preparar Buenos Aires para inaugurar o Pan. Os antagonismos entre os usos políticos do esporte pelo governo peronista e os princípios defendidos pelo COI tornaram-se cada vez mais evidentes entre 1948 e 1951, como se observa nos documentos analisados.

Os preparativos para o Pan a ser inaugurado em 1951 mobilizaram o governo argentino, que criou um ambiente em que a prática de esportes era incentivada como um fator essencial para a construção de uma "Nova Argentina," incluindo, para isso, a imagem popular da primeiradama Eva Perón. As aspirações do governo Perón podem ser mais bem entendidas em uma resolução publicada pelo COA, em que se lê: "[...] competições esportivas inspiram o desejo de vencer por parte daqueles que participam, gerando um amplo e constante movimento que contribui para a melhora da atitude para o benefício da saúde moral e física da raça."11

Brundage (1948), por sua vez, argumentava que a política não deveria interferir no esporte, pois, "[...] concepções políticas arrastam a juventude para um terreno perigoso, tendo em vista que não há outro objetivo na política senão CONTROLE e PODER sobre os esportistas, o que é completamente destoante dos ideais olímpicos" [grifo do autor]. ${ }^{12} \mathrm{O}$ posicionamento de Brundage sobre os atletas era completamente antagônico, por exemplo, à visão peronista sobre 0 assunto, que considerava os atletas como "[...] os melhores embaixadores de um país", ou seja, agentes importantes para projetar uma imagem positiva da Argentina para o exterior.

O investimento financeiro foi maciço para a preparação dos Jogos. Mas o uso político do Pan não passou despercebido por membros de organizações esportivas internacionais. O membro do COI peruano Alfredo Benavides escreveu uma reclamação formal para Avery Brundage, dizendo:

9 O Brasil, por exemplo, estabeleceu o Conselho Nacional de Desportos em 1941 e o colocou diretamente sobre a administração do Ministério da Educação e Saúde Pública. Em 31 de março de 1944, Brundage enviou uma carta à Confederação Brasileira de Desportos manifestando preocupação quanto a isso (GUTTMANN, 1984, p.135).

10 BRUNDAGE, Avery. Procés-Verbale, 21 Abr. 1949, Coleção Avery Brundage, Western University, Caixa 76, Bobina de Microfilme n. 100. 11 COMITÊ OLÍMPICO ARGENTINO. Primeiros Jogos Pan-Americanos. Resolução N.1, Buenos Aires, 14 nov. 1949. Coleção Avery Brundage, Caixa 202, Bobina de Microfilme n.117.

12 BRUNDAGE, Avery. Relatório da Assembleia de Delegados do Segundo Congresso Pan-Americano. Londres, 8 ago. 1948. Coleção Avery Brundage, Western University, Caixa 202, Bobina de Microfilme n.117. 
Os Jogos Pan Americanos poderiam ser uma oportunidade brilhante para disseminar os princípios e propósitos do movimento olímpico. Mas, há um desvio de finalidade do evento devido à excessiva intervenção do governo em assuntos do esporte. ${ }^{13}$

Entretanto, pelo que consta nos documentos, Brundage não deu seguimento a grandes discussões a respeito do tema, alegando que tais questões seriam tratadas em reunião dos membros da ODEPA durante os Jogos em Buenos Aires.

Os Jogos Pan-Americanos foram inaugurados em 25 de fevereiro de 1951. Vinte países participaram do evento, dentre eles: Brasil, Costa Rica, Colômbia, Cuba, Paraguai, Peru, Uruguai e Venezuela. Autoridades do esporte prestaram homenagens a Perón e à sua esposa Eva Perón pela contribuição deles para a inauguração do Pan. Protocolos da cerimônia foram repletos de elementos simbólicos que emularam os Jogos Olímpicos e discursos políticos foram proferidos sobre a "Nova Argentina". Quando o presidente argentino declarou os Jogos abertos, uma bandeira olímpica foi hasteada no estádio oficialmente chamado de "Presidente Juan Domingo Perón."

Brundage proferiu um discurso na abertura reiterando a importância do elo entre as Américas e o COI:

É um prazer cumprimentá-los nesta noite na Argentina, nesse primeiro encontro de membros do COI, creio eu, na América do Sul e, também, no hemisfério Sul [...] Precisamos de mais membros do COI na América Latina [...] Será bom para o COI e bom para a América Latina. $^{14}$

Brundage considerou a primeira edição do Pan um sucesso. Apesar disso, relatórios dele para o COI sobre a organização do evento demonstraram preocupação:

Estou feliz em reportar que tivemos excelente cooperação em nossos esforços de manter os preparativos em conformidade com as regras de amadorismo e os padrões olímpicos. Erros foram cometidos, é verdade, mas eles se devem, parcialmente, à inexperiência [...] Praticamente todo o esporte amador em países da América Latina é financiado pelos governos nacionais. Como consequência, há muita interferência política. Recomenda-se que o COI inicie uma campanha educativa para assistir os Comitês Olímpicos Nacionais nesta área [...] Órgãos governamentais deveriam ser informados que é apropriado que eles controlem a Educação Física, os programas de saúde e treinamento esportivo nas escolas, mas, a direção do esporte amador competitivo deveria ficar a cargo das federações nacionais e Comitês Olímpicos Nacionais, que devem ser livres, independentes e autônomos (BRUNDAGE, 1951b, p. 37-39).

Embora, a princípio, os membros latinos da ODEPA tenham reivindicado a autonomia da entidade frente a instituições europeias, o Pan enfatizou símbolos, protocolos e regras olímpicas em seus Jogos. Essa emulação liderada por autoridades do esporte estava ancorando-se no prestígio que o COI já tinha no cenário internacional e essa conexão favorecia o desejado sucesso do Pan. Visibilidade era importante para essa finalidade. Outra questão é certamente ideológica. Aceitar, compartilhar e promover mensagens ideológicas positivas relacionadas ao esporte é uma tarefa fácil na medida em que elas se relacionam com valores universais comuns, positivamente relacionados a princípios éticos. 
Os atletas argentinos ganharam mais medalhas que qualquer outra equipe nacional naquela primeira edição do Pan. Muitos deles dedicaram suas vitórias a Perón. Ao mesmo tempo em que aquele evento foi considerado um sucesso, houve diferentes reações ao evento.

A mídia impressa argentina fez referências positivas ao evento, ressaltando a organização e a projeção internacional positiva da imagem do país. Autoridades do esporte argentino consideraram o sucesso do Pan como uma demonstração de que Buenos Aires poderia sediar os Jogos Olímpicos no futuro, incluindo o próprio presidente Perón (TORRES, 2014). Por outro lado, parte da mídia impressa americana comparou o uso político do Pan com os Jogos Olímpicos de forte propaganda nazista em 1936. ${ }^{15}$

O Pan de 1951 compôs um cenário interessante quanto à realização de eventos esportivos internacionais na América do Sul. Países da região tiveram experiências como: a I Copa do Mundo de Basquetebol em 1950, na Argentina; A Copa do Mundo de Futebol no Brasil naquele mesmo ano; O campeonato Mundial de Voleibol no Brasil em 1960; o Pan em São Paulo em 1963. Embora o futebol já fosse o esporte dominante na América do Sul, a ideia de sediar eventos multiesportivos como meio de promoção de uma imagem internacional (política e não política), juntamente com o potencial do esporte de fortalecer os sentimentos nacionalistas e impulsionar desenvolvimento urbano, direcionou os interesses de organizações esportivas e, claro, autoridades políticas.

A realização do Pan em 1955 e 1959 enfrentou sérias dificuldades operacionais, logísticas e financeiras. Avery Brundage tornou-se presidente do COI e a organização do Pan ficou sob a liderança de outro norte-americano, Douglas F. Roby. Apesar de tais dificuldades, por causa do seu caráter multiesportivo, o Pan não tardou a se tornar uma realização que as cidades-sede utilizariam como credencial para candidatar-se a sediar futuros Jogos Olímpicos. Países da América do Sul, como Brasil e Argentina, participaram de todas as edições consecutivas com um aumento no número de equipes representativas e o interesse regular em sediar o evento, como foi o caso de São Paulo, em 1963.

\section{CONCLUSÕES}

Em suma, a partir dos dados analisados, dois argumentos se destacaram em relação à proposta de estabelecer os Jogos Pan-Americanos, sobretudo, na década de 1940 (quando a proposta do evento se consolidou), a saber: 1 . 0 papel diplomático dos Jogos, que visava promover relações Inter-Americanas ancoradas no que foi denominado de "pan-americanismo"; 2. A visão idealística implicada no evento (a posteriori), que visava difundir os valores e regras do Movimento Olímpico. Em geral, autoridades esportivas e de governos da América Latina engajaram-se para a realização dos Jogos Pan-Americanos segundo os moldes, protocolos e regras do Movimento Olímpico, porém, como se demonstrou nesse estudo, com seus interesses particulares e, comumente, antagônicos ao movimento idealista em torno de competições esportivas internacionais, sobretudo a negação da interferência política sobre eles.

Apesar de preocupações relacionadas à proliferação de jogos regionais, é razoável argumentar que Avery Brundage buscou acomodar estes eventos sob a tutela do COI como uma opção melhor do que rivalizá-los. Para isso, Brundage negligenciou seus próprios 
entendimentos sobre a interferência política no esporte, preferindo permitir a materialização do evento na Argentina peronista do que o contrapor, sob a alegação de que a América Latina precisava ser instruída a respeito das regras do $\mathrm{COI}$.

Este estudo demonstrou que autoridades esportivas dos EUA e da Europa perceberam nos Jogos Pan-Americanos não só um desafio, mas uma oportunidade para promover regras e ideais do Movimento Olímpico moderno na América Latina. $O$ argumento central é que os Jogos Pan-Americanos contribuíram para o processo de enraizamento do Movimento Olímpico na América Latina como resultante das interações entre lideranças do COI, dos Estados Unidos da América e Europa com autoridades políticas e do esporte das Américas Central e do Sul. Análises posteriores poderão apontar os direcionamentos organizacionais da ODEPA após anos dirigida por norte-americanos, bem como a interação subordinada desta instituição ao COI e as implicações disso para o esporte olímpico e pan-americano.

\section{REFERÊNCIAS}

BRUNDAGE, Avery. Relatório da Comissão apontada pelo COI para estudar as condições na América Latina. Olympic Review, n. 27, mar. 1951b, p. 37-39. Disponível em: <http://library.la84. org/OlympicInformationCenter/OlympicReview/1951/BDCE27/BDCE27n.pdf.> Acesso em: 20 jan. 2015.

GUTTMANN, Allen. The Games Must Go On: Avery Brundage and the Olympic Movement. New York: Columbia University Press, 1984.

LEONARD, Thomas M.; BRATZEL, John F. (Org.). Latin America During World War II. Lanham: Rowman \& Littlefield, 2006.

MCGEHEE, Richard V. The Origins of Olympism in Mexico: The Central American Games of 1926. The International Journal of the History of Sport, v. 10, n. 3, p. 313-332, dez. 1993.

PIMENTEL, Alessandra. O método da análise documental: seu uso numa pesquisa historiográfica. Caderno Pesquisa, n. 114, p. 179-195, nov. 2001. Disponível em: <http://www. scielo.br/scielo.php?script=sci_arttext\&pid=S010015742001000300008\&lng=en\&nrm=iso>. Acesso em: 16 mar. 2017.

ROCHE, Maurice. Mega-Events and Modernity: Olympics and expos in the growth of global culture. London: Routledge, 2000.

SANTOS, Doiara Silva dos. Avery Brundage, Pan-American Games, and Entrenchment of the Olympic Movement in Latin America. 2015. $227 \mathrm{f}$. Tese (Doutorado) - Curso de Educação Física, Departamento de Ciências da Saúde, Western University, London, 2015. Disponível em: <http://ir.lib.uwo.ca/cgi/viewcontent.cgi?article=5042\&context=etd>. Acesso em: 15 dez. 2017.

SENN, Alfred. Power, Politics and the Olympic Games: a history of the Power Brokers, events, and controversies that shaped the Games. Champaign: Human Kinetics, 1999.

TAVARES, Otavio. Megaeventos esportivos. Movimento, v. 17, n. 3, p. 11-35, jul./set. 2011. 
TORRES, César. Jogos Olímpicos Latino-Americanos: Rio de Janeiro 1922. Manaus: Confederação Brasileira de Atletismo, 2012.

TORRES, César. The limits of Pan-Americanism: the case of the failed 1942 Pan American Games. The International Journal of the History of Sport, v. 28, p. 2547-2574, dez. 2011.

TORRES, César. Peronism, International Sport, and Diplomacy. In: DICHTER, Heather; JOHNS, Andrew. Diplomatic Games: Sport, Statecraft, and International Relations since 1945. Lexington: The University Press of Kentucky, 2014. p. 151-182. 
